\title{
Treatment of neonatal infections: a multi-country analysis of health system bottlenecks and potential solutions
}

\author{
Aline Simen-Kapeu1*, Anna C Seale², Steve Wall ${ }^{3}$, Christabel Nyange ${ }^{1,4}$, Shamim A Qazi ${ }^{5}$, Sarah G Moxon ${ }^{3,6,8}$, \\ Mark Young ${ }^{1}$, Grace Liu', Gary L Darmstadt ${ }^{9}$, Kim E Dickson ${ }^{1}$, Joy E Lawn ${ }^{3,6,8}$
}

\begin{abstract}
Background: Around one-third of the world's 2.8 million neonatal deaths are caused by infections. Most of these deaths are preventable, but occur due to delays in care-seeking, and access to effective antibiotic treatment with supportive care. Understanding variation in health system bottlenecks to scale-up of case management of neonatal infections and identifying solutions is essential to reduce mortality, and also morbidity.

Methods: A standardised bottleneck analysis tool was applied in 12 countries in Africa and Asia as part of the development of the Every Newborn Action Plan. Country workshops involved technical experts to complete a survey tool, to grade health system "bottlenecks" hindering scale up of maternal-newborn intervention packages. Quantitative and qualitative methods were used to analyse the data, combined with literature review, to present priority bottlenecks and synthesise actions to improve case management of newborn infections.

Results: For neonatal infections, the health system building blocks most frequently graded as major or significant bottlenecks, irrespective of mortality context and geographical region, were health workforce (11 out of 12 countries), and community ownership and partnership (11 out of 12 countries). Lack of data to inform decision making, and limited funding to increase access to quality neonatal care were also major challenges.

Conclusions: Rapid recognition of possible serious bacterial infection and access to care is essential. Inpatient hospital care remains the first line of treatment for neonatal infections. In situations where referral is not possible, the use of simplified antibiotic regimens for outpatient management for non-critically ill young infants has recently been reported in large clinical trials; WHO is developing a guideline to treat this group of young infants. Improving quality of care through more investment in the health workforce at all levels of care is critical, in addition to ensuring development and dissemination of national guidelines. Improved information systems are needed to track coverage and adequately manage drug supply logistics for improved health outcomes. It is important to increase community ownership and partnership, for example through involvement of community groups.
\end{abstract}

\section{Background}

Neonatal (0-28 days) deaths account for an estimated $44 \%$ of deaths in children under age 5 years [1]. Around one-third of these, (640,000 in 2013) are caused by neonatal infections, including the clinical syndromes of sepsis, meningitis and pneumonia [1]. In total, there were an estimated 6.1 million cases of possible serious bacterial

\footnotetext{
* Correspondence: askapeu@unicef.org

${ }^{1}$ Health Section, Programme Division, UNICEF Headquarters, 3 United

Nations Plaza, New York, NY 10017, USA

Full list of author information is available at the end of the article
}

infection (PSBI) in South Asia, sub-Saharan Africa in 2012 [2]. As well as mortality, these neonatal infections cause impairment and disability $[2,3]$. Newborns most at risk are preterm and/or low birth weight $[4,5]$. Prevention measures include immunisation [6,7], anti-sepsis [8-11], and exclusive breastfeeding $[12,13]$. For those who do become sick, timely detection of newborn illness with appropriate case management could prevent an estimated $84 \%$ of neonatal infection deaths $[14,15]$.

Newborns with infections can rapidly deteriorate and prompt identification and treatment are needed. Clinical 
algorithms are used to guide initiation of treatment, as part of the Integrated Management of Childhood Illness (IMCI) (Figure 1). Inpatient hospital care is the cornerstone of management of severe neonatal infection (Figure 2) [16]. WHO guidelines recommend sick newborns identified in the community are referred and admitted to a health facility for supportive care and treatment [17-19]; however, referral is not always possible. To improve access to care, simplified antibiotics for non-critically ill newborns can be safely provided by trained and supervised health workers as outpatients, if referral is not possible, as reported in recent clinical trials [6-8]. WHO is expected to soon release guideline for management of possible serious bacterial infection (PSBI) where referral is not possible.

Most critical, and most challenging, is transforming health systems to overcome barriers to improve treatment of newborn infections [9]. There are many preventable deaths, due to delays in diagnosis [10], care seeking, and treatment [11]. Healthcare constraints likely include a lack of trained health workers, and limited financial resources, as well as socio-cultural issues (reducing access to care) [20,21]. Health systems research aiming to identify bottlenecks to delivery, affordability, and sustainability of high-impact interventions to reduce mortality from newborn infections was recently highlighted as a research priority [12].

This paper is part of a nine paper series on quality maternal and newborn care and aims to describe intervention and context-specific health system bottlenecks, with potential solutions, for improved case management of neonatal infections. Care of small and sick newborns is detailed elsewhere in this series [22,23]. Specifically, the objectives of this paper are to:

1. Use a 12-country analysis to explore health system bottlenecks affecting the treatment of neonatal infections.

2. Present solutions to overcome the most significant bottlenecks including learning from the 12-country analyses, literature review and programme experience.

3. Discuss policy and programmatic implications and propose priority actions for the treatment of neonatal infections.

Results will guide sharpening of health programme priorities and policy and strengthen implementation of the Every Newborn Action Plan to end preventable newborn deaths by 2030 [13].

\section{Methods}

This study used quantitative and qualitative research methods to collect information, assess health system bottlenecks and identify solutions to the scale up of neonatal infection case management. Other maternal and newborn care interventions were assessed as part of this process and are described elsewhere in the series. The participating countries were Afghanistan, Cameroon, Democratic Republic of Congo (DRC), Kenya, Malawi, Nigeria, Uganda, Bangladesh, India, Nepal, Pakistan and Vietnam, expanding on a smaller subset as published in The Lancet Every Newborn series [9].

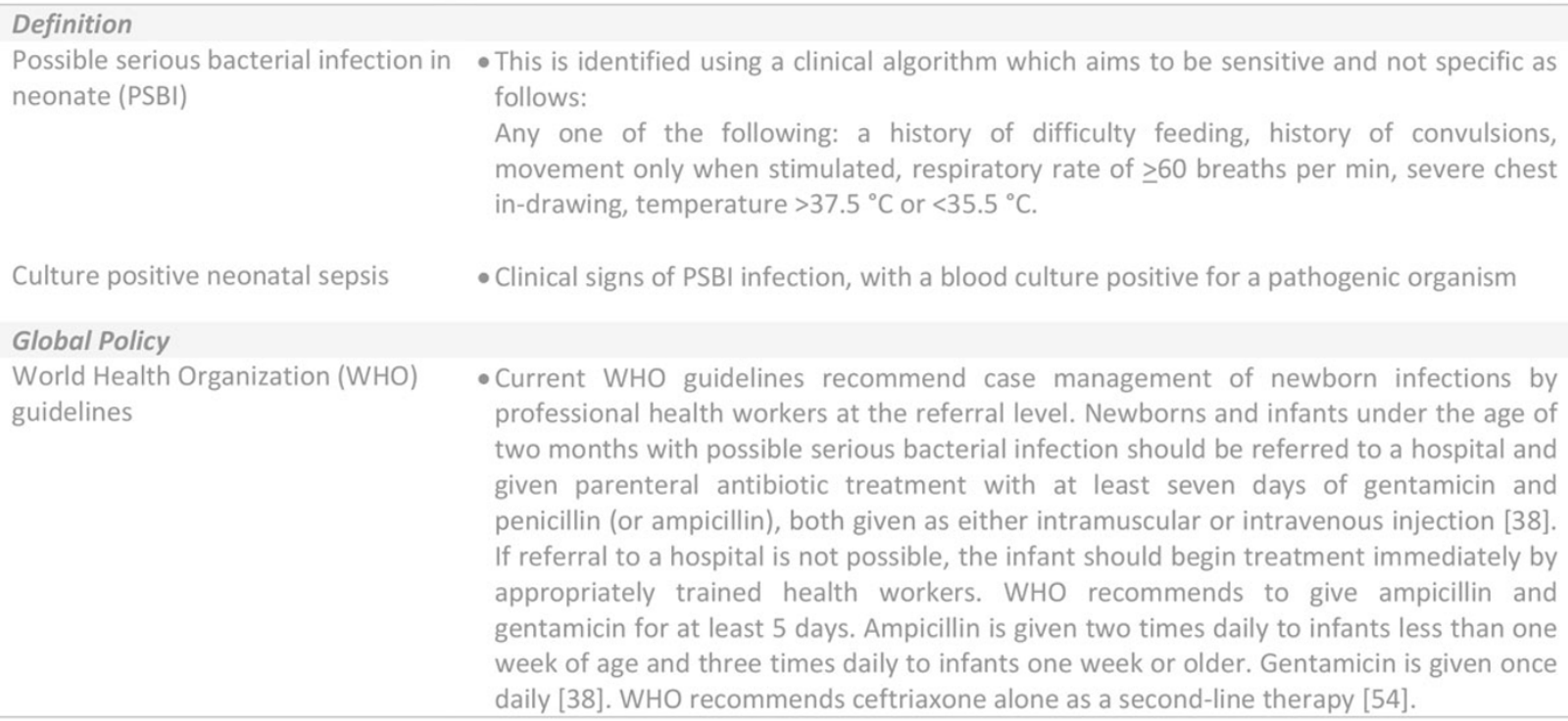

- Current WHO guidelines recommend case management of newborn infections by professional health workers at the referral level. Newborns and infants under the age of two months with possible serious bacterial infection should be referred to a hospital and given parenteral antibiotic treatment with at least seven days of gentamicin and penicillin (or ampicillin), both given as either intramuscular or intravenous injection [38]. If referral to a hospital is not possible, the infant should begin treatment immediately by appropriately trained health workers. WHO recommends to give ampicillin and gentamicin for at least 5 days. Ampicillin is given two times daily to infants less than one week of age and three times daily to infants one week or older. Gentamicin is given once daily [38]. WHO recommends ceftriaxone alone as a second-line therapy [54].

Figure 1 Clinical algorithm for neonatal infection and World Health Organization recommended treatment. PSBI: possible serious bacterial infection; WHO: World Health Organization. 


\section{Inpatient care of small and sick newborns}

Full case management and supportive care for neonatal infections

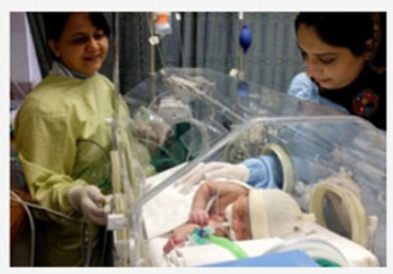

\section{Inpatient care}

for newborns with neonatal
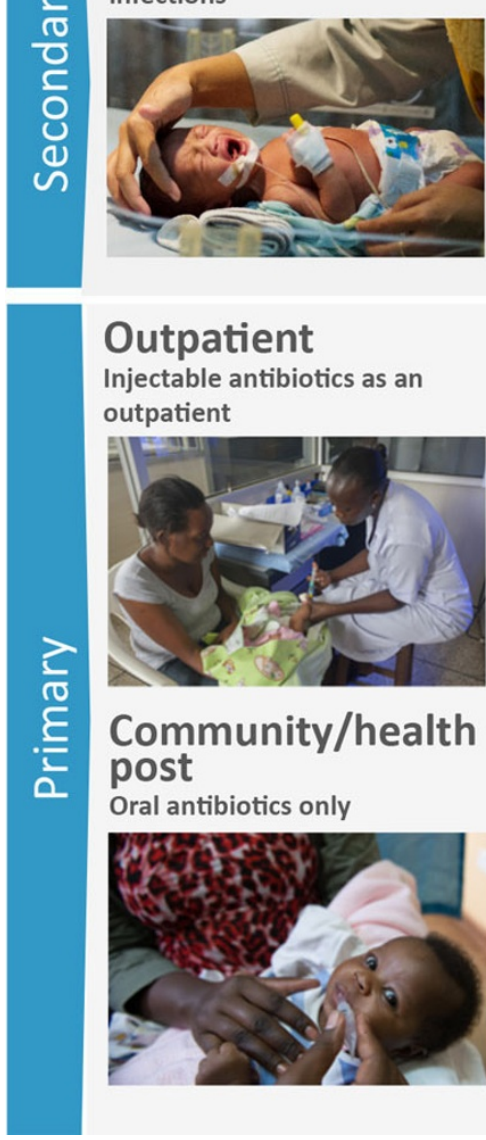

\section{Outpatient}

Injectable antibiotics as an outpatient

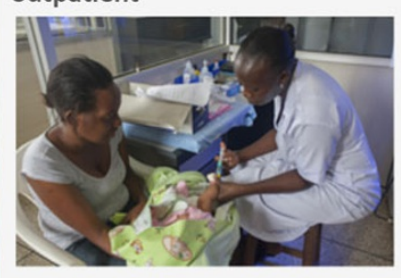

\section{Community/health}

\section{post}

Oral antibiotics only

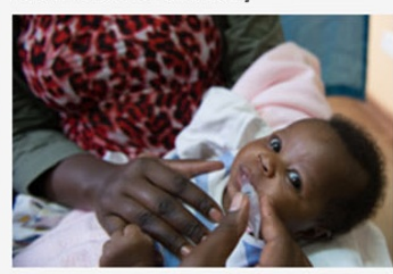

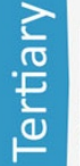

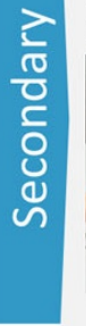

- Inpatient in a hospital facility (see inpatient care of small and sick newborns)

- Midwives and nurses specialised in newborn care

People. At least one doctor with specialised neonatal training newborns)

In addition to neonatal intensive and special care equipment:

- Possible serious bacterial infection (PSBI) diagnostic algorithms, or may be more advanced assessments/investigations e.g. lab tests/ cultures

Equipment and commodities

- Injectable antibiotics (course may be completed as oral)

- If needed also second line injection antibiotics, intravenous fluids, oxygen therapy and pulse oximetry and nasogastric tube feeding

- Access to full inpatient supportive care for small and sick newborns Support - 24 hour laboratory support system - Transport and referral if needed

- Space for mother and family to stay close to their baby.

Equipment and - Cannula, injectable antibiotics, diagnostic algorithms

- Oxygen, pulse oximetry, nasogastric feeding tubes and intravenous fluids (if required)

- Referral to higher level of care as required

Support system - Transport and referral if needed

- Support for breastfeeding commodities

Place - Primary care or facility as outpatient (e.g. where referral is not possible)

- Midwives or nurses skilled in integrated management of childhood illness (IMCl) and newborn care

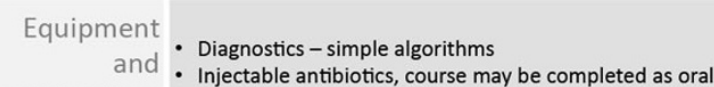

Support system - Referral to higher level care as required

$\begin{aligned} & \text { Place } \begin{array}{l}\text { Most commonly as outpatient, in some cases at community health post } \\ \text { (e.g. where referral is not possible) }\end{array} \\ & \text { People } \text { Trained health workers } \\ & \begin{aligned} \text { Equipment and } \\ \text { commodities }\end{aligned} \\ & \text { - Diagnostic algorithm } \\ & \text { Oral antibiotics }\end{aligned}$

Figure 2 Treatment of neonatal infections, showing health system requirements by level care. Inpatient care of small and sick newborns image source: Ayesha Vellani/Save the Children. Inpatient care image source: Syane Luntungan/Jhpiego. Outpatient care image source: Ian P. Hurley/Save the Children. Community/health post care: Hannah Maule-ffinch/Save the Children. PSBI: possible serious bacterial infection; IMCS: integrated management of childhood illness. 


\section{Data collection}

The maternal-newborn bottleneck analysis tool (see Additional file 1) was developed to assist countries in the identification of bottlenecks to the scale up and provision of nine maternal and newborn health interventions across the seven health system building blocks, as described previously $[9,16]$. The tool was utilised during a series of national consultations supported by the global Every Newborn Steering Group between $1^{\text {st }}$ July and $31^{\text {st }}$ December 2013. The workshops for each country included participants from national Ministries of Health, United Nations agencies, the private sector, non-governmental organisations, professional bodies, academia, bilateral agencies and other stakeholders. For each workshop, a facilitator, orientated on the tool, coordinated the process and guided groups to reach consensus on the specific bottlenecks for each health system building block.

Tracer interventions were defined for each package of interventions to focus the workshop discussion. The use of injectable antibiotics was selected as a tracer indicator for quality care provided to newborns with neonatal infection.

\section{Data analysis methods}

Data received from each country were reviewed, consolidated, and categorised by the Every Newborn study group as described below. The graded health system building blocks were converted into heat maps (Figures 3 and 4). Bottlenecks for each health system building block were graded using one of the following options: not a bottleneck (=1), minor bottleneck (=2), significant bottleneck
(=3), or very major bottleneck (=4). The number of countries from which workshop participants categorised health system bottlenecks as significant or very major are presented by mortality context (Neonatal Mortality Rate $(\mathrm{NMR})<30$ deaths per 1000 live births and NMR $\geq 30$ deaths per 1000 live births) and region (Africa or Asia). Grading of health system bottlenecks by individual countries was also described.

Context specific solutions to overcome challenges were categorised into thematic areas and linked to specific bottlenecks. A literature review was undertaken to identify further case studies and evidence-based solutions for each defined thematic area. For a detailed description of the steps taken to analyse the intervention specific bottlenecks, refer to the overview paper [16].

\section{Results}

Twelve countries were included in this exercise: Afghanistan, Cameroon, Democratic Republic of Congo (DRC), Kenya, Malawi, Nigeria, Uganda, Bangladesh, Nepal and Vietnam returned national level responses. Pakistan provided subnational data from all provinces apart from two territories which were Gilgit-Baltistan and Azad Jammu and Kashmir. India returned subnational data from three states: Andhra Pradesh, Odisha and Rajasthan (see Additional file 2). Data on suggested strategies and solutions were missing for Uganda and two provinces in Pakistan. However, bottleneck data from these countries were available and included in the analysis.

Overall, the bottlenecks rated by country teams as very major or significant health system bottlenecks ( $\geq 75 \%$ of countries) were as follows: health workforce

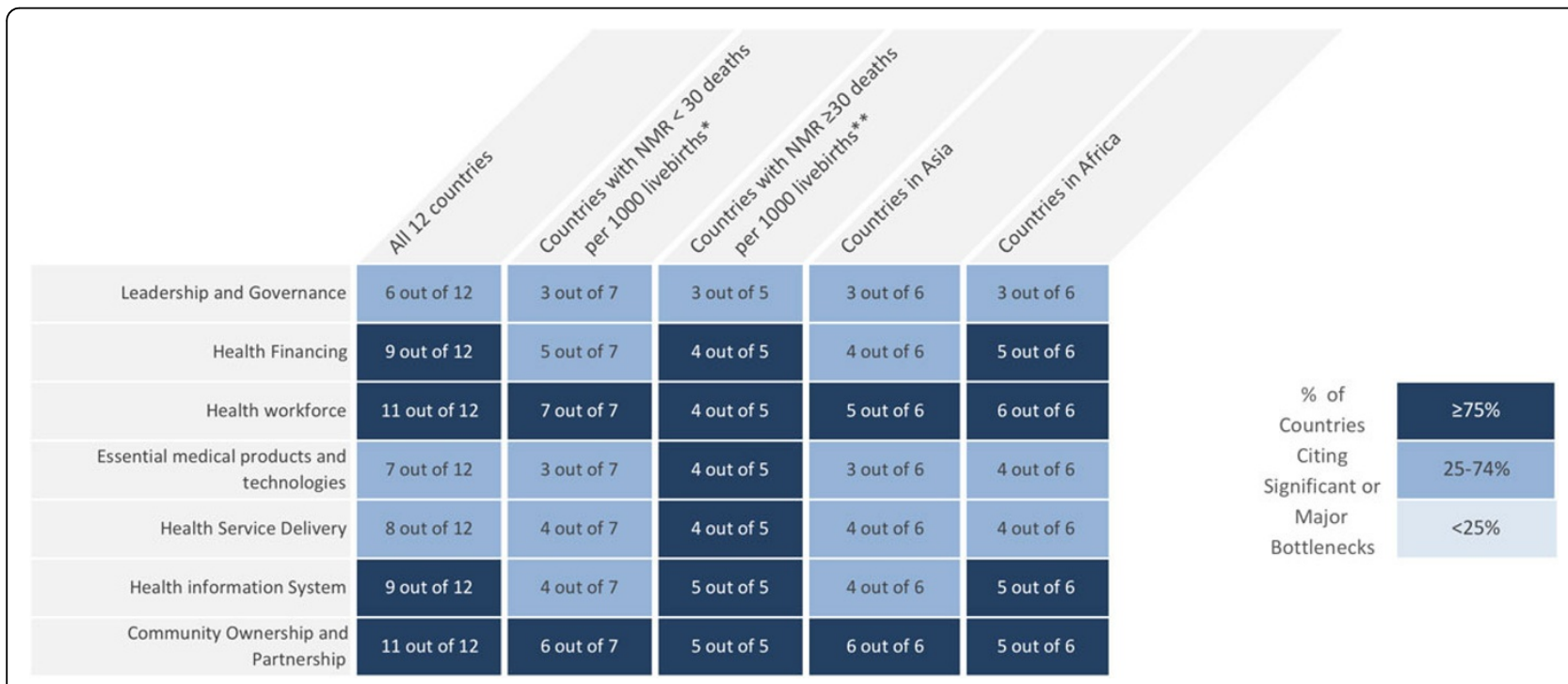

Figure 3 Very major or significant health system bottlenecks for treatment of neonatal infections. NMR: Neonatal Mortality Rate. *Cameroon, Kenya, Malawi, Uganda, Bangladesh, Nepal, Vietnam. ${ }^{*}$ Democratic Republic of Congo, Nigeria, Afghanistan, India, Pakistan. See Additional file 2 for more details. 


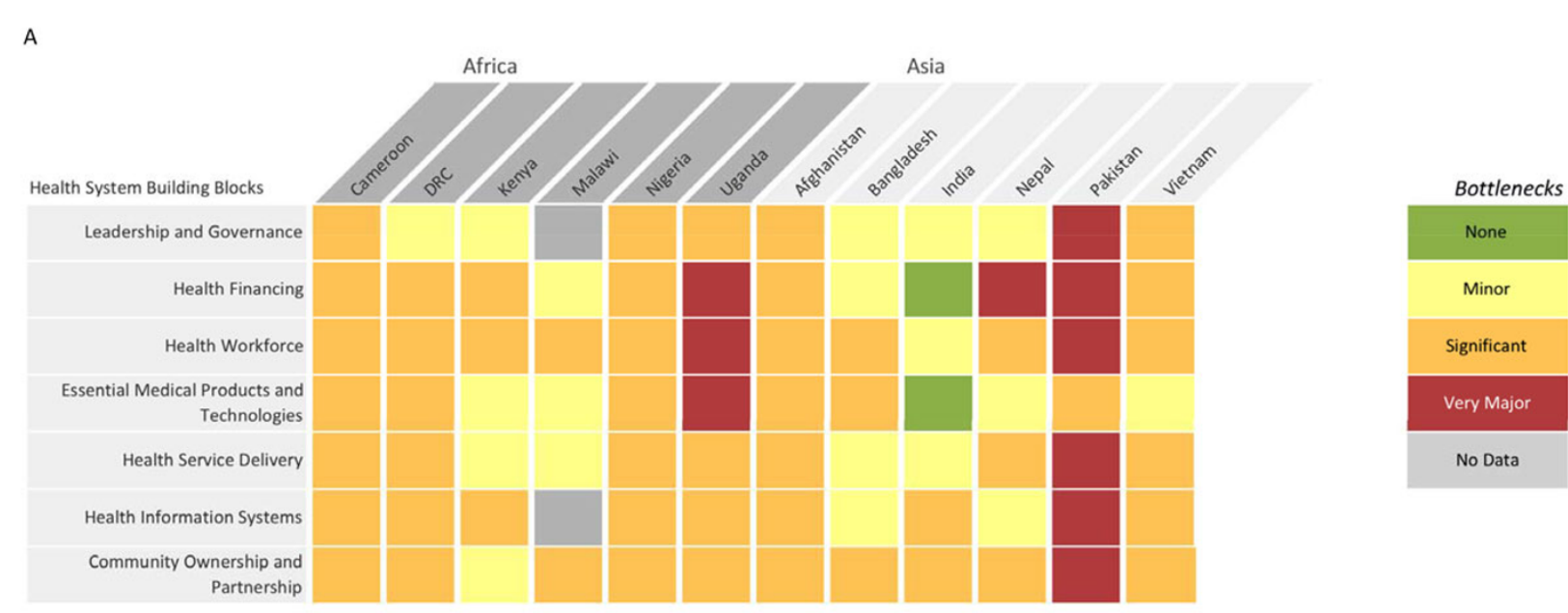

B

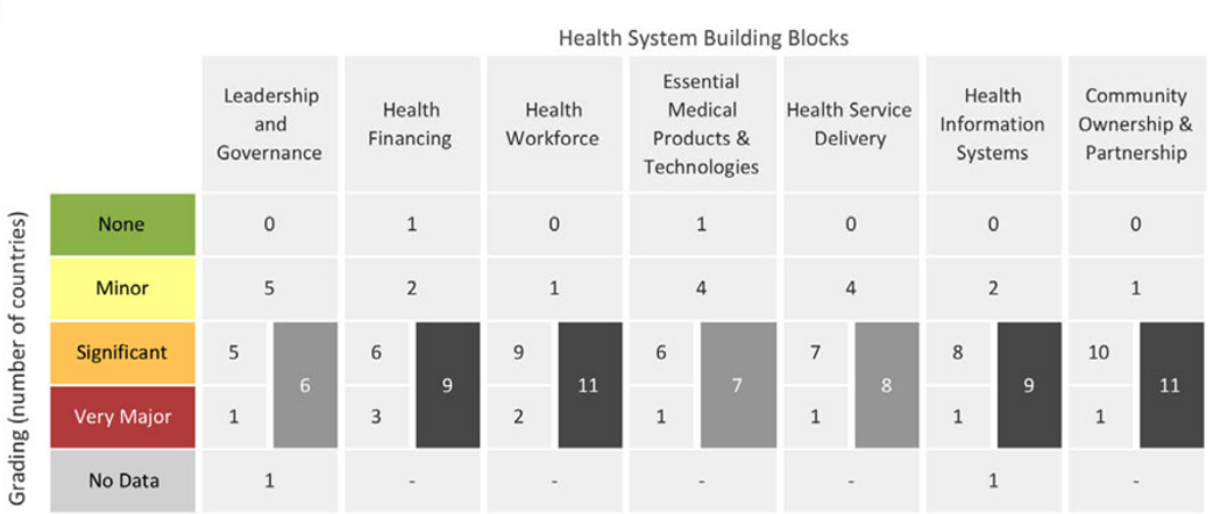

Figure 4 Individual country grading of health system bottlenecks for treatment of neonatal infections. Part A: Heat map showing individual country grading of health system bottlenecks for treatment of neonatal infections. Part B: Table showing total number of countries grading significant or major for calculating priority building blocks. DRC: Democratic Republic of the Congo.

(11 out of 12 countries), community ownership and partnership (11 out of 12 countries), health financing (9 out of 12 countries) and health management information systems ( 9 out of 12 countries) (Figure 3 ).

Minor regional differences were observed in the grading; very major or significant bottlenecks related to health financing and health management information system were reported by 5 out of 6 country teams from Africa and 4 out of 6 country teams from Asia. More notable differences were identified by mortality context. For countries with high NMR ( $\geq 30$ deaths per 1000 live births), all the health system building blocks except for leadership and governance were cited as very major or significant bottlenecks by at least 4 out of 5 country teams ( $\geq 75 \%$ of countries) (Figure 3 ).

Common bottlenecks to optimal management of neonatal infections (reported by at least 3 countries) and their potential solutions are described below (summarised in Table 1 and Table 2) for the seven health system building block categories.

\section{Leadership and governance bottlenecks and solutions}

Policies for prescription and administration of antibiotics by qualified health workers only at referral (secondary or tertiary) hospitals, and not primary care level, were identified as one of the most important barriers to effective case management of neonatal infections by workshop participants ( 7 out of 12 country teams). Others included absence or poor dissemination (especially to primary care) of practice guidelines/protocols on treatment of neonatal infections.

Proposed solutions included development or review of national policies and guidelines on prevention and management of neonatal infections with the support of professional bodies. Country teams suggested these should include guidance on management of neonatal infections in primary health care facilities, including specification of the role of community health workers. In addition, workshop participants suggested disseminating guidelines to all health care providers, including in private settings. 
Table 1. Summary of solution themes and proposed actions for treatment of neonatal infections

\begin{tabular}{|c|c|c|}
\hline $\begin{array}{l}\text { Health system building } \\
\text { block }\end{array}$ & Solution themes & Proposed actions \\
\hline $\begin{array}{l}\text { Leadership and } \\
\text { governance }\end{array}$ & $\begin{array}{r}\text { Policy/guidelines review, } \\
\text { harmonisation and dissemination } \\
\text { Task shifting policy } \\
\text { Harmonisation and dissemination of } \\
\text { guidelines }\end{array}$ & $\begin{array}{l}\text { - Review / formulation of policies and strategies: integration of neonatal care within } \\
\text { integrated management of childhood illnesses (IMCI) and scale up of this at primary } \\
\text { care level; } \\
\text { - Shifting care and treatment at the outpatient level where referral is not possible- } \\
\text { Expansion/implementation of community-based MNH programmes } \\
\text { - Harmonise guidelines for management of neonatal infections at all level of care: } \\
\text { engage professional bodies and private health care institutions } \\
\text { - Ensure effective dissemination of guidelines (workshops, websites) }\end{array}$ \\
\hline Health financing & $\begin{array}{r}\text { Funding for newborn health } \\
\text { National insurance schemes } \\
\text { expansion }\end{array}$ & $\begin{array}{l}\text { - Increase budget allocated for newborn health: ensure adequate resources for } \\
\text { trainings of health workers, laboratory services, and commodities including } \\
\text { injectable antibiotics } \\
\text { - Expand health insurance schemes to address out-of-pocket payments: expansion } \\
\text { of community-based health insurance schemes (e.g.: inclusion of fees required at } \\
\text { teaching hospitals and for laboratory tests into insurance schemes }\end{array}$ \\
\hline Health workforce & $\begin{array}{l}\text { Local recruitment of health workers } \\
\text { Institutionalisation of incentives } \\
\text { Competency-based skilled based pre- } \\
\text { service and in-service training }\end{array}$ & $\begin{array}{l}\text { - Recruit local staff residing in the community to expand the availability of health } \\
\text { care workers in all areas } \\
\text { - Motivate health providers through institutionalisation of incentives to improve } \\
\text { their retention in rural and hard to reach areas such as improved welfare packages } \\
\text { or wages, hardship allowances, pay for performance } \\
\text { - Conduct large scale pre-service and in-service trainings of health care workers in } \\
\text { newborn care including management of neonatal infections; enhance the quality of } \\
\text { trainings provided through supervision, mentoring and certification systems; involve } \\
\text { medical colleges and institutions; train community-based health care workers in } \\
\text { newborn care for home visits and identification of sick young infants }\end{array}$ \\
\hline $\begin{array}{l}\text { Essential medical } \\
\text { products and } \\
\text { technologies }\end{array}$ & $\begin{array}{r}\text { Procurement and supply chain } \\
\text { management system } \\
\text { Quality control mechanisms }\end{array}$ & $\begin{array}{l}\text { - Strengthen the national procurement and supply system: Forecast adequate } \\
\text { amount of injectable antibiotics according to the needs for treatment and based } \\
\text { on the buffer to be kept; Streamline the procurement process including fast } \\
\text { tracking of essential commodities; Special equipment like, Continuous positive } \\
\text { airway pressure, portable x-ray, and arterial blood gas analyser should made } \\
\text { available for tertiary care centres; } \\
\text { - Establish quality control mechanisms: Auditing of medical stores; facility } \\
\text { assessments of those reporting frequent stock-outs; assessment of the quality of } \\
\text { antibiotics in the bidding process; ensure the delivery of quality products; Develop } \\
\text { an electronic logistic management system }\end{array}$ \\
\hline
\end{tabular}

\section{Health financing bottlenecks and solutions}

Seven out of 10 country workshop participants reported insufficient funding for procurement, and continuous, sustainable distribution of antibiotics. High out-of-pocket expenses, arising from consultancy fees, transport, and treatment, as well as some unofficial payments, were a burden for families, especially for second and third line antibiotics. Limited coverage of financing schemes and insurance mechanisms for care of sick newborns was highlighted by all country teams.

Workshop participants called for more advocacy, engaging women's groups and professional associations, to support increased funding for newborn care and strengthen procurement and distribution of supplies and drugs, including antibiotics, at all levels of health care. Notably some countries with community-based insurance schemes, such as Indonesia, do not include newborns since registration takes a month.

A few country teams suggested that the challenge of out-of pocket expenses could be mitigated by including free consultation in medical colleges as part of a national treatment scheme, as is done in some countries such as Bangladesh and Vietnam, or establishing health insurance schemes including community-based insurance schemes.

\section{Health workforce bottlenecks and solutions}

Eleven out of twelve country teams indicated a shortage of health care workers with adequate knowledge and skills to competently identify and manage newborn infections, especially in primary care settings. Retaining professional, well-trained health workers in rural areas is challenging. Mentorship and supervision structures were 
Table 2. Summary of solution themes and proposed actions for treatment of neonatal infections (continued)

\begin{tabular}{|c|c|c|}
\hline $\begin{array}{l}\text { Health system } \\
\text { building block }\end{array}$ & Solution themes & Proposed actions \\
\hline Health service delivery & $\begin{array}{r}\text { Mobile outreach MNH services/ } \\
\text { post-discharge counselling } \\
\text { Community/home-based } \\
\text { maternal and newborn care } \\
\text { Two way referral system for sick } \\
\text { newborns } \\
\text { Quality assurance/ improvement } \\
\text { mechanisms }\end{array}$ & $\begin{array}{l}\text { - Ensure post-discharge counselling on danger signs for newborns; } \\
\text { - Scale-up newborn care at the lower level of care: Strengthen the provision of } \\
\text { newborn care, especially sepsis case management at outpatient/primary health centre } \\
\text { level where referral is not possible, institutionalise home visits / domiciliary care by } \\
\text { trained personnel; Expand mobile outreach MNH services to make newborn services } \\
\text { closer to the community } \\
\text { - Strengthen two way referral system for sick newborns; } \\
\text { - Establish quality assurance mechanisms: a quality assurance cell at the state/national } \\
\text { level with regular quality assessments with emphasis on supportive supervision and } \\
\text { mentoring by medical colleges and private hospitals; national scale-up of clinical audits } \\
\text { and perinatal death reviews; Periodic critical review of appropriate management of } \\
\text { newborn infections; Regular review and dissemination of quality of care check lists }\end{array}$ \\
\hline $\begin{array}{l}\text { Health information } \\
\text { system }\end{array}$ & $\begin{array}{r}\text { Electronic reporting systems } \\
\text { Processes and evidence-based } \\
\text { decision -making }\end{array}$ & $\begin{array}{l}\text { - Develop electronic reporting system: software apps for record keeping on newborn } \\
\text { interventions including neonatal sepsis management and establishing linkages from } \\
\text { facility to community } \\
\text { - Strengthen data collection and reporting for newborn care: disaggregate the data in } \\
\text { the health management information system to include newborn health interventions, } \\
\text { especially management of severe neonatal infections; add community data and } \\
\text { postnatal consultations; develop neonatal registers; and set up a monitoring system for } \\
\text { hospital infection prevention } \\
\text { - Establish review processes; analyse and use data on management of neonatal } \\
\text { infections to inform performance review meetings and for quality improvement } \\
\text { processes } \\
\text { - Enhance research in newborn care: conduct bacterial surveillance and antibiotics } \\
\text { resistance studies; conduct newborn survival analysis to inform programme managers }\end{array}$ \\
\hline $\begin{array}{l}\text { Community ownership } \\
\text { and participation }\end{array}$ & $\begin{array}{r}\text { Development/review of local IEC } \\
\text { materials }\end{array}$ & $\begin{array}{l}\text { - Development/review of local IEC materials: emphasize benefits of newborn care } \\
\text { services, mainly within the first week of life } \\
\text { - Fee exemption for newborn care and functional referral system as well as for } \\
\text { maternity care. } \\
\text { - Strengthen community-based activities: education on hand washing and personal } \\
\text { hygiene, behaviour change communication activities for educating caretakers on } \\
\text { identification and prompt care seeking and to tackle harmful cultural beliefs, awareness } \\
\text { campaigns using multiple channels to increase knowledge, demand for postnatal and } \\
\text { community-based newborn care, and empower women. } \\
\text { - Engage male partners in MNH care: Encourage male participation in ANC, labour, } \\
\text { delivery and post natal visit. }\end{array}$ \\
\hline
\end{tabular}

described as non-functional and incentives to motivate staff, support job satisfaction, and career development were lacking.

Workshop participants suggested that pre-service and in-service training are opportunities to reinforce knowledge and skills of health workers in newborn infection case management for primary, secondary and tertiary levels of care. Country teams suggested that welltrained, supervised and incentivised health workers could initiate oral antibiotic treatment in specific contexts where referral was not possible. Capacity strengthening and professional development of health care workers could be reinforced by improving supervision and mentoring, in collaboration with medical colleges and private institutions. In some settings, country teams suggested a computer-based training for ongoing in-service training and updates.

\section{Essential medical products and technologies bottlenecks and solutions}

A common challenge reported was inefficiency of procurement and supply management systems ( 9 out of 12 country teams), leading to erratic antibiotic supply. There are manufacturing gaps, and limited distribution of supplies, as well as inadequate systems for forecasting and restocking. Consequently there are frequent stock-outs and prescription of alternative, second line antibiotics. There was also a need to strengthen laboratory services.

Proposed strategies include strengthening systems by improving management skills, warehousing capacity, and 
supporting a distribution system at subnational levels to ensure accurate forecasting and adequate management of stocks. Regular audits of medical stores and hospital pharmacies should be institutionalised, dependent on leadership and governance (discussed above).

\section{Health service delivery bottlenecks and solutions}

A major concern from eight out of twelve country teams was inadequate referral systems between community, primary and secondary health facilities, causing delays in access to the appropriate level of care and treatment of newborn infections. There was inadequate recognition and referral of newborns with infection at primary health care facilities, partly due to lack of trained staff and supportive policy.

Quality of care was an important barrier for optimal management of neonatal infections at all levels of the health system. Country teams highlighted the absence of guidelines for neonatal infection management in health facilities and/or lack of adherence to these guidelines when available. Hospital-acquired infection prevention was not well implemented and audits of maternalperinatal care were rare, and did not include the assessment for newborn infections based on risk factors.

Country teams suggested that increasing access to care should start with strengthened referral systems. Publicprivate sector partnerships and community-led transportation systems were suggested. Where referral is not possible, workshop participants suggested appropriately trained nurses and midwives may potentially be able to instigate treatment.

It was suggested that quality of care in facilities could be improved with regular use of checklists and audits of case management of neonatal infection, as well as perinatal death reviews. Guidelines for infection control, with adherence assessed through supervision by district health teams, were suggested.

\section{Health information system bottlenecks and solutions}

There were ten out of twelve country teams who reported failure to collect data on management of neonatal infections, including data on antibiotic use, due to the lack of indicators for treatment of newborn infections in health information systems. Most country teams also highlighted that clinical records for sick and small newborns were inadequate at all levels of care.

Data collection and reporting tools should be reviewed to ensure indicators for treatment of newborn infection are part of routine systems. Electronic recording systems were suggested to strengthen data collection and reporting within facilities and to support evidence-based improvement of performance. Country teams proposed innovative tools, for example data collection via mobile phones by community health workers.

\section{Community ownership and partnership bottlenecks and solutions}

Workshop participants from both Africa (3 countries) and South Asia (3 countries) highlighted the practice of a period of seclusion (usually around one month) after birth where mothers and babies stay indoors in some settings. If mothers or babies become ill during this period, care seeking is often delayed. This may be exacerbated by poor knowledge and recognition of signs of infections, delay in reaching appropriate care because of large distances to health facilities, and delay in receiving appropriate care and antibiotic treatment due to financial barriers (e.g. consultation fees in teaching hospitals or costs of second line antibiotics). Poor adherence to full treatment for neonatal infections was a challenge exacerbated by limited involvement of family members and communities.

Behaviour change activities should be strengthened, working with local community groups and leaders to emphasise the importance of early care-seeking for newborn illness and recognition of danger signs. Engagement of male partners during antenatal care, delivery, post discharge counselling, and postnatal visits is important. Inclusion of the benefits of early health care seeking for neonatal infection and adherence to treatment should be advocated by facility-based health care workers and communicated in local languages, empowering health workers at all levels.

\section{Discussion}

To the best of our knowledge this is the first in-depth multi-country analysis of specific health system bottlenecks and strategies to address the management of neonatal infections. Neonatal infections are one of the main causes of neonatal deaths, and most of these deaths are in low-income countries where health systems are the most challenged. These twelve countries account for over $60 \%$ of the world's neonatal and maternal mortality and a similar proportion of stillbirths, and yet have varying contexts and health system strengths and weaknesses.

The participatory approach involved a wide range of programmatic and technical expertise. The process of the bottleneck analysis allowed for consensus-based data capture of context-specific challenges, barriers and possible solutions, from a diverse group of ground-level stakeholders and experts in twelve high burden countries. Together these countries account for the majority of maternal and newborn deaths [9]. Our results will sharpen health programme priorities and policies, and strengthen implementation of the Every Newborn Action Plan to end preventable neonatal deaths by 2035 [13], noting that many countries are already making health system changes [17].

These results suggest that community-level ownership and the health workforce are priority health system 
areas to improve to scale-up the treatment of neonatal infections. The lack of emphasis on newborn infection management at policy and programme level, lack of financial resources for care and quality data on neonatal infection case management, were also identified and graded by country teams as key challenges. It is essential that there is harmonisation and dissemination of newborn guidelines at all levels of care, and expansion of pre-service and in-service training for health care workers. Access to care must be improved, including by offering outpatient treatment for neonatal infection when referral is not possible, strengthening home-based newborn care, and engaging local communities to increase education and demand for quality healthcare services.

\section{Community ownership and partnership priority actions}

It is important, even for hospital births (where women and their newborns may be discharged quickly), that women, families and communities are empowered to rapidly recognise and respond to danger signs if they occur. The time from first clinical signs to severe illness or death may be only a few hours. Maternal education, and engagement of fathers and extended family, will help families respond appropriately when their children are sick, including recognising danger signs with immediate care-seeking for treatment $[18,19]$. Prevention is beyond the scope of this paper, but community ownership and partnership have important roles in this too; for example hygiene and treatment of maternal infections and basic newborn care [15,22], which are described elsewhere in this series [24,25].

\section{Referral systems}

To achieve reductions in newborn mortality, strengthened referral systems are needed between all levels of care (primary, secondary and tertiary, see Figure 2), for rapid access to hospital based care for severe neonatal infections [26]. Barriers to adherence to referral include financial and logistical challenges as well as preference (with social and cultural influences). It is important to clearly define referral mechanisms (for example verbal, written, or referral slips), assess locally available resources for emergency communication (radio contact with facilities) and transport (community committees) to support implementation of community-based health programmes; including costs and logistics of transport and referral systems $[20,23,27,28]$. Several countries have shown that community-led referral systems or public-private partnerships can improve access to primary and secondary care. In Nigeria a loan fund was successfully linked with an initiative to involve local car owners in a stand-by transport scheme for emergency referrals [29]. In Mali, referral loan funds are managed by local health committees [30]. There is limited evidence on effectiveness, and implementation at scale of these referral mechanisms. The long-term objective should be to assess and establish operational referral systems for maternal, newborn and child emergencies (and elective referrals) as part of the district health system. Maximal benefits are achieved through improving both clinical care and referral systems $[31,32]$.

\section{Health workforce priority actions}

One of the greatest challenges is the gap in the availability and distribution of qualified health care workers to manage neonatal infections at all levels of health care (Figure 2). Management of neonatal infections, including administration of antibiotics, is usually restricted to doctors in secondary and tertiary hospitals. Our analysis showed that challenges to providing high quality care are often related to the low numbers of specialist staff with skills to manage newborn illness (midwives, trained nurses, paediatricians, neonatologists). The lack of trained nurses and a global neonatal nursing cadre is explored in greater detail elsewhere in the series, and is critical for supportive care such as safe administration of intravenous fluids and oxygen [33]. A strategy involving simple structural improvements, in-service training opportunities, effective team-based mentoring and supervision could strengthen the capacity of providers to care for newborns. The quality of primary health care is limited by weak supervision systems, poor implementation of guidelines and protocols and a lack of staff trained to diagnose and treat newborn infections. Trained community health workers and extension workers can play an important role in recognition of illnesses, supporting families to adopt healthy practices and seek care, encouraging delivery in a health care facility, identifying sick young infants and ensuring timely referral $[27,34]$. For example, in Nepal, neonates with PSBI were identified at home as needing treatment by well-trained facility-based workers and referred for care. Treatment was initiated in $90 \%$ of the PSBI episodes; and $93 \%$ of newborns completed a full course of gentamicin [35].

There are some instances, however, when families may not, or cannot accept timely referral for care [6-8]. Management of neonates with PSBI with simpler antibiotic regimens where referral is not possible is a real need in many low resource settings. At present there is divergence across countries in policy and practice regarding outpatient treatment of neonatal infections; a recent review showed that 6 of 59 countries had permissive policies, and 11 of 59 countries (most in southern Asia) were implementing outpatient treatment of neonatal infections at different scales (sub-national or district level programmes) [36]. Recently large trials have reported that when hospital-based inpatient treatment is not feasible, 
simpler antibiotic regimens are effective when provided on an outpatient basis to non-critically sick neonates with PSBI, thereby increasing treatment for neonates who currently have little or no access to care (Figure 5) [6-8]. However, it is unlikely that one policy will meet the needs of all countries, given the different infrastructures, and a country-by-country approach is likely to be appropriate (Figure 6). Outpatient treatment should not become a substitute for hospital inpatient care (the standard of care), and requires close monitoring, supervision, and coordination with health facilities [34,37].

\section{Guidelines and policies}

Diagnosis, referral and treatment of neonatal infections is directed by international guidelines; primary-level recognition and management of danger signs have been added to integrated management of childhood illness (IMCI)

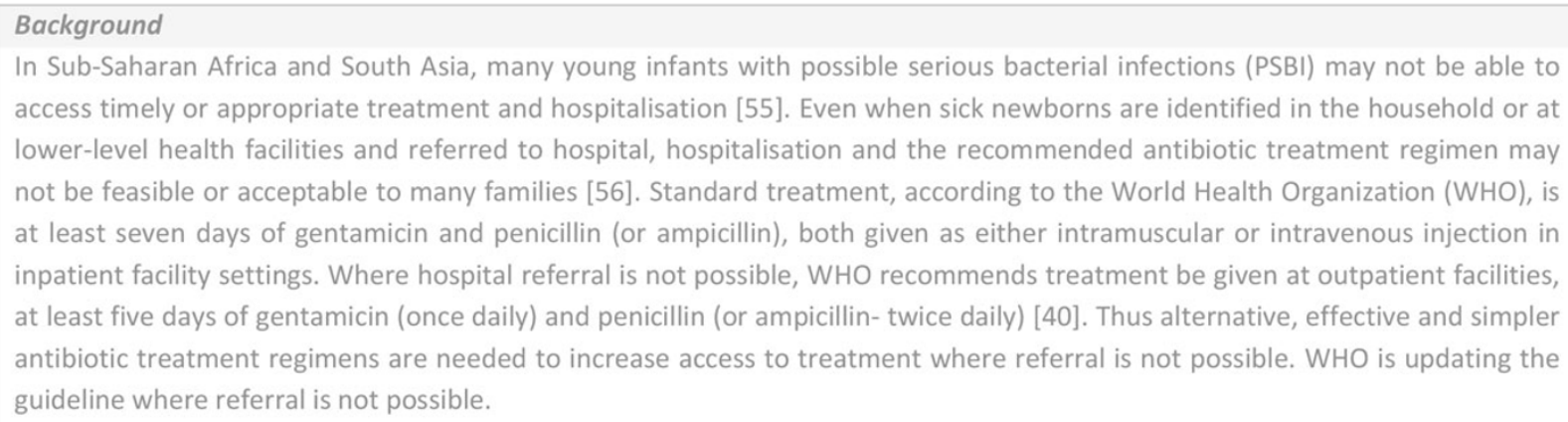

\section{Approach}

Understanding the challenges and barriers that exist for families to access appropriate treatment for very sick newborns, three studies, known as SATT-Pakistan, SATT-Bangladesh and AFRINEST (Nigeria, Kenya, DRC) [6-8], were designed to evaluate simpler, alternative antibiotic regimens for outpatient management of young infants with PSBI in cases where families did not or could not accept hospital referral. These studies were large, individually randomised-controlled trials, embedded in the context of a program setting, designed to provide home visits by community health workers trained to detect serious illness in young infants with assessment and treatment at an outpatient health facility near home. The trials measured treatment failure rates, comparing the reference regimen to three alternative antibiotic regimens for clinical severe infection ${ }^{1}$ :

- Arm A (reference regimen): intramuscular procaine penicillin once daily and gentamicin once daily for 7 days (total of 14 injections)

- Arm B: intramuscular gentamicin once daily and oral amoxicillin twice daily for 7 days (total of 7 injections)

- Arm C: intramuscular procaine penicillin once daily and gentamicin once daily for 2 todays, followed by oral amoxicillin twice daily for 5 days (total of 4 injections; but requires 3 different drugs)

- Arm D (tested only in AFRINEST): intramuscular gentamicin once daily and oral amoxicillin twice daily for 2 days, followed by oral amoxicillin twice daily for 5 days (total of 2 injections)

For young infants with fast breathing as an isolated sign, the AFRINEST trial also compared the reference regimen to Arm E, comprised of oral amoxicillin twice daily for 7 days (no injections).

It should be noted that critically ill young infants were not included in these trials. ${ }^{2}$

\section{Implications}

The results have provided new evidence that simpler antibiotic regimens could be provided in outpatient settings when hospital-based treatment of severe non-critical neonatal infection is not possible or not accepted by families. Such simpler options are likely lead to increased treatment of severe infections in newborns who currently have little or no access to effective treatment.

Figure 5 Innovative treatment regimens for possible severe infections. The Simplified Antibiotic Therapy Trial (SATT) and African Neonatal Sepsis Trial (AFRINEST) study groups. ${ }^{1}$ In a young infant (0-59 days old), at least one sign of severe infection (i.e. movement only when stimulated, not feeding well on observation, temperature greater than or equal to $38^{\circ} \mathrm{C}$ or less than $35.5^{\circ} \mathrm{C}$ or severe chest in-drawing. ${ }^{2}$ In a sick young infant, presence of any of the following signs - unconscious, convulsions, unable to feed at all, apnoea, unable to cry, cyanosis, bulging fontanelle, major congenital malformations inhibiting oral antibiotic intake, active bleeding requiring transfusion, surgical conditions needing hospital referral, persistent vomiting defined as vomiting following three attempts to feed the baby within 30 minutes. AFRINEST: African Neonatal Sepsis Trial; PSBI: possible serious infection; SATT: Simplified Antibiotic Therapy Trial; WHO: World Health Organization. 


\begin{abstract}
Background
In Ethiopia, the neonatal mortality rate remains high at 37 deaths per 1,000 live births; many of these newborns die from preventable causes, with $28 \%$ directly due to severe infections (e.g. sepsis, pneumonia, and meningitis). Most of these deaths could be averted through the application of known preventive maternal and newborn interventions (e.g. hygiene, cord care), and timely and appropriate treatment with antibiotics. Facility birth rates in Ethiopia are low and many newborns do not have access to health facilities and doctors or other qualified health professional trained to prescribe and administer antibiotics; this often results in life-threatening delays in antibiotic treatment or, in many cases, no antibiotic treatment at all.
\end{abstract}

\title{
Approach
}

The Ethiopia Federal Ministry of Health (FMOH) established the Health Extension Programme (HEP) in 2006, which has trained and deployed approximately 34,000 Health Extension Workers (HEWs) deployed at health posts, each serving a population of approximately 5000 people. While originally designed as a preventive and health promotion programme, HEP was recognised as a potentially important task-shifting opportunity to provide integrated community case management (iCCM) for childhood illnesses; from 2010, this included treatment for pneumonia. Based on $\mathrm{ICCM}$ experience, along with learning from a large research study (COMBINE) (in press at the time of this writing), the FMOH designed and started implementing Community-Based Newborn Care (CBNC) in 2014. HEWs are trained to recognise and refer newborns with signs of possible serious bacterial infection (PSBI), and provide outpatient treatment with antibiotics when referral is not possible or not accepted by families. HEWs are supported by a network of volunteers known as the Health Development Army to enable household-level maternal and newborn practices and care seeking. The regimen used in COMBINE, and implemented in CBNC when referral is not possible or not accepted, is outpatient treatment with a 7-day course of once-daily injectable gentamicin given by HEW at the health post, and twice daily oral amoxicillin given by the HEW at the time of injection and by the family in the evening. No monitoring data is yet available from CBNC, but COMBINE experience demonstrated a large increase in PSBI case recognition and treatment at health posts in the intervention arm, where HEW provided PSBI management in the community. Cases of PSBI identified and treated at health centres remained low and unchanged from the comparison arm, which did not provide health post treatment when referral to health centre was not possible or not accepted.

\section{Lessons learned and implications}

The ultimate success of a task-shifting approach for PSBI when referral is not possible or not accepted will depend upon the necessary investments to ensure follow up of treated PSBI cases, monitoring of coverage and quality, supervision, health worker skills maintenance, medicine availability, and a functioning logistics management system. This Ethiopia experience provides an important example for other countries to use task shifting strategies to provide life-saving antibiotics to newborns with PSBI, but who have no access to standard hospital-based treatment.

Figure 6 Where referral is not possible: Task shifting the management of newborn potential serious infection to health extension workers in Ethiopia. 1. Federal Ministry of Health: Health Extension program in Ethiopia. Health Extension and Education Center, Addis Ababa, Ethiopia June 2007 http://www.moh.gov.et/documents/36477/47416/HEW+profile+Final+08+07/da2fcc1a-6f38-4958-9ebf-a3310ec830c3;jsessionid = 054B89019E2E2ED40995C98D0D8D94B8?version = 1.0 2. Special Issue: Integrated Community Case Management (iCCM) at Scale in Ethiopia: Evidence and Experience. Ethiopia Medical Journal, Volume 52, Supplement 3, October, 2014. CBNC: community-based newborn care; FMOH: Federal Ministry of Health; HEP: health extension programme; HEWs: health extension workers; iCCM: integrated community case management; PSBI: possible serious bacterial infection.

guidelines [38]. IMCI has been shown to reduce neonatal mortality when implemented at high coverage $[21,39,40]$, but lack of investment in recent years means it is not always fully implemented at peripheral level facilities, where it is most needed [41]. Guidelines in health facilities, and especially including job aids (e.g. gentamicin nomograms, or for intravenous fluid administration or nasogastric feeding) posted on the ward walls can help improve case management of sick neonates and children, and yet are often lacking, as noted in these 12 country 
assessments. Poor leadership support, staff shortages, and inadequate training and supervision to recognise and manage neonatal infections, as well as lack of basic supplies could be reasons for limited adherence to guidelines [42-44]. WHO is developing a guideline to treat non-critically sick neonates, where referral is not possible with simpler antibiotic regimens, which will soon be available.

At all levels of care there is a need for better management of drug supplies, with inclusion of neonatal formulations of antibiotics in facilities, and logistics monitoring and forecasting systems [45]. Safety concerns administering antibiotics are important and documentation, training and supervision are needed to ensure correct dosage and administration. Aminoglycoside antibiotics, such as gentamicin, are widely used and have the potential for toxicity above certain threshold levels, but data are limited [46] and routine therapeutic monitoring is often not done even in facilities in low and middle income countries. Improving availability of drugs with clear indications on neonatal dosage (especially gentamicin) may encourage greater adherence and simplify supply logistics [44].

\section{Other priority actions}

Quality data are lacking on neonatal care, which limits the ability to track and evaluate service provision for the management of neonatal infections. Major data quality gaps include data on antibiotic use in the perinatal period and outcome data for neonatal infection. Demographic and Health Surveys (DHS) and Multiple Indicator Cluster Surveys (MICS) capture care seeking and treatment for fever and symptoms of acute respiratory infections for all children under five years, however, the sample is often too small for disaggregation, and data are not specifically presented for newborns. Improving availability of routine statistics through strengthening national/district health information systems should be a priority. More attention needs to be paid to the development and testing of indicators for treatment of neonatal infections and their inclusion in health management information systems to increase facility-based reporting [47]. Data collection through health workers using mobile phone technologies could improve quality data compilation and reporting at the health facility $[48,49]$.

The lack of clinical audit and case review to assess the management of neonatal infection and the related deaths was highlighted by African country teams. The introduction of perinatal has the potential to reduce mortality when solutions are linked to action [50]. However, operationalising this in low-income countries remains a challenge [51], which is discussed in more detail elsewhere in the series[52].

\section{Limitations}

The data generated from the workshop came from consensus views of participating national stakeholders including government representatives and experts and may be subjective. The quality and amount of information extracted from these workshops varied depending on the level of knowledge of participants on health system issues and facilitation. Sub-national data (two out of 28 states) received from India, the highest contributor of global neonatal deaths, were compiled as one input and may not be generalisable to the whole country; these two states are amongst the most marginalised and may represent a worst case scenario.

Another limitation was that bottlenecks were reported as perceived bottlenecks relative to other health system building blocks. There may be instances where known health system challenges, or deficits based on robust quantitative data, are in conflict with the perceived bottleneck grading. This could arise due to the method of grading relative to other health system building blocks, or because participants placed higher subjective value on other areas of their health system. Another explanation is that groups may view certain building block areas as easier to overcome, based on knowledge and experience of their setting, and the specific newborn intervention being discussed. The tool is comprehensive and detailed - which is one of its strengths. However, it also may have caused some workshop fatigue, particularly towards the end of the workshop where teams discussed and recorded solutions. For example, for the neonatal sepsis questionnaires, Pakistan completed the bottleneck portion of the questionnaires, but did not submit any solutions.

\section{Research agenda}

The challenges and varying health system contexts discussed underline the need for implementation research on this topic, particularly around the "how to" questions. There is a need for better tracking of safety outcomes (for example after gentamicin use), monitoring of antimicrobial resistance and development of point of care diagnostics. WHO, UNICEF and Save the Children are facilitating several African and Asian countries to set up small scale demonstration sites for simplified management of sick newborns with PSBI as outpatients, where referral is not possible. Coverage data for treatment of newborn infections are lacking and it may not be feasible to use household surveys [53]; improving the metrics for tracking programmatic quality is crucial [47].

\section{Conclusions}

To reduce the burden of neonatal mortality, improving management, as well as preventing, neonatal infections is essential. Key messages and action points from this 


\section{Key messages}

- Infections are a major cause of neonatal mortality, responsible for approximately one third of the total neonatal deaths worldwide, and a higher proportion in high mortality settings. Timely recognition of illness in sick young infants, appropriate care seeking and access to appropriate treatment is needed to reduce the neonatal mortality.

- The provision of high quality care for neonatal infections is hampered by health systems challenges in both Asia and Africa. The highest ranked bottlenecks by the 12 countries assessed were community ownership and health workforce, irrespective of mortality context and geographical region.

\section{Key action points}

- Increase community capacity to recognise and address maternal and newborn complications, including signs of possible serious bacterial infection (PSBI) and for families, including women to be able to take decisions to seek care. Strategies may include women's groups, particularly in rural settings with low access to primary health services.

- Invest more in referral systems and also communication linkages for transport. Where referral is not possible, governments may decide to provide simplified antibiotic therapy by trained health workers in an outpatient setting. However this will still require supervisory systems, a functional health management information system (HMIS) and supply logistics system.

- Increased investment, especially in health workforce with specific skills for newborn care, is critical at all levels of the health system. In facilities, more health workers are needed and it is critical to ensure pre-service education includes rapid recognition and competency based training for sick and small newborns, as one the most sensitive markers of health system function.

Figure 7 Key messages and action points for treatment of neonatal infections

paper are summarised in Figure 7. Even with a weak health system, measurable mortality reduction can be achieved by starting with communities and primary care, up to tertiary levels, and addressing the highest priority health system bottlenecks; a skilled workforce and community participation and ownership. There is a critical need for improved access to antibiotic treatment at all levels of care, in addition to supportive care, with strong referral systems. There is an urgent need to increase investment, and to train more health care workers in neonatal care. Every country must prioritise assessment of their health system and ensure a programme is being implemented to reach every newborn.

\section{Additional material}

Additional file 1: Bottleneck tool questionnaire

Additional file 2: Supplementary tables and figures.

\section{List of abbreviations}

DHS: Demographic and Health Surveys; DRC: Democratic Republic of Congo; HEWs: Health Extension Workers; IMCl: Integrated Management of Childhood Illness; MICS: Multiple Indicator Cluster Surveys; NMR: Neonatal Mortality Rate; PSBI: possible serious bacterial infection; WHO: World Health Organization.

\section{Competing interests}

All authors declare they have no competing interests. The assessment of bottlenecks expressed during consultations reflects the perception of the technical experts and may not be national policy. The authors alone are responsible for the views expressed in this article and they do not necessarily represent the decisions, policy or views of the organisations listed, including $\mathrm{WHO}$.

\section{Authors' contributions}

AS-K was responsible for the tool development, conceptualisation of the paper, substantial contributions to the data analysis, and writing. ACS oversaw the analysis and writing of the paper; CN contributed to data process, analysis, and literature review; KED was responsible for the overall coordination of the country consultation process, bottleneck analysis tool development and reviews of the paper drafts. SGM, SW, GLD, SQ, MY, JEL contributed sections of text and reviewed paper drafts. All named authors contributed to paper drafts and approved the final manuscript. 


\section{Acknowledgements}

This work would not have been possible without the country technical working groups and country workshop organiser and participants who did the bottleneck analyses. We would like to thank Helen Owen at LSHTM for her assistance with figures, and Fiorella Bianchi for her assistance with the submission process and the additional files. Finally, we would like to thank Dr Salim Sadruddin and Dr Ayede Adejumoke Idowu for their helpful peer reviews of this manuscript.

\section{Declarations}

Publication of this supplement was funded by the Bill and Melinda Gates Foundation through a grant to US Fund for UNICEF (Grant ID: OPP1094117), and support from Save the Children's Saving Newborn Lives Programme. Additional funding for the bottleneck analysis was received from USAID (Grant ID: GHA-G-00-07-00007) through UNICEF.

This article has been published as part of BMC Pregnancy and Childbirth Volume 15 Supplement 2, 2015: Every Woman, Every Newborn. The full contents of the supplement are available online at http://www. biomedcentral.com/bmcpregnancychildbirth/supplements/15/S2.

\section{Authors' details}

${ }^{1}$ Health Section, Programme Division, UNICEF Headquarters, 3 United Nations Plaza, New York, NY 10017, USA. ${ }^{2}$ University College London Department of Infectious Diseases Informatics, UCL Institute for Health Informatics, Farr Institute, 222 Euston Road, London NW1 2DA, UK. ${ }^{3}$ Saving Newborn Lives, Save the Children, 2000 L Street NW, Suite 500, Washington, DC 20036, USA. ${ }^{4}$ Ross University Medical School, 2300 SW 145th Avenue, Miramar, FL 33027, USA. ${ }^{5}$ Department of Maternal, Newborn, Child and Adolescent Health, World Health Organization, Avenue Appia 20, 1211 Geneva 27, Switzerland. 'Maternal, Adolescent, Reproductive and Child Health (MARCH) Centre, London School of Hygiene and Tropical Medicine, London, WC1E 7HT, UK. ${ }^{7}$ Save the Children Federation, Inc., 501 Kings Highway East, Suite 400, Fairfield, CT 06825, USA. ${ }^{8}$ Department of Infectious Disease Epidemiology, London School of Hygiene and Tropical Medicine, London, WC1E 7HT, UK. ${ }^{9}$ Department of Pediatrics, Stanford University School of Medicine, Stanford, CA 94305 USA.

Published: 11 September 2015

\section{References}

1. Lawn JE, Blencowe H, Oza S, You D, Lee AC, Waiswa P, et al: Every Newborn: progress, priorities, and potential beyond survival. Lancet 2014, 384(9938):189-205.

2. Seale AC, Blencowe H, Manu AA, Nair H, Bahl R, Qazi SA, et al: Estimates of possible severe bacterial infection in neonates in sub-Saharan Africa, south Asia, and Latin America for 2012: a systematic review and metaanalysis. The Lancet infectious diseases 2014, 14(8):731-741.

3. Murray CJ, Vos T, Lozano R, Naghavi M, Flaxman AD, Michaud C, et al: Disability-adjusted life years (DALYs) for 291 diseases and injuries in 21 regions, 1990-2010: a systematic analysis for the Global Burden of Disease Study 2010. Lancet 2012, 380(9859):2197-2223.

4. Waters D, Jawad I, Ahmad A, Luksic I, Nair H, Zgaga L, et al: Aetiology of community-acquired neonatal sepsis in low and middle income countries. Journal of global health 2011, 1(2):154-170.

5. Thaver D, Zaidi AK: Burden of neonatal infections in developing countries: a review of evidence from community-based studies. Pediatr Infect Dis J 2009, 28(1 Suppl):S3-9.

6. African Neonatal Sepsis Trial group, Tshefu A, Lokangaka A, Ngaima S, Engmann C, Esamai F, et al: Oral amoxicillin compared with injectable procaine benzylpenicillin plus gentamicin for treatment of neonates and young infants with fast breathing when referral is not possible: a randomised, open-label, equivalence trial. Lancet 2015, 385(9979):1758-1766.

7. African Neonatal Sepsis Trial group, Tshefu A, Lokangaka A, Ngaima S, Engmann C, Esamai F, et al: Simplified antibiotic regimens compared with injectable procaine benzylpenicillin plus gentamicin for treatment of neonates and young infants with clinical signs of possible serious bacterial infection when referral is not possible: a randomised, openlabel, equivalence trial. Lancet 2015, 385(9979):1767-1776.

8. Baqui AH, Saha SK, Ahmed AS, Shahidullah M, Quasem I, Roth DE, et al: Safety and efficacy of alternative antibiotic regimens compared with 7 day injectable procaine benzylpenicillin and gentamicin for outpatient treatment of neonates and young infants with clinical signs of severe infection when referral is not possible: a randomised, open-label, equivalence trial. The Lancet Global health 2015, 3(5):e279-287.

9. Dickson KE, Simen-Kapeu A, Kinney MV, Huicho L, Vesel L, Lackritz E, et al: Every Newborn: health-systems bottlenecks and strategies to accelerate scale-up in countries. Lancet 2014, 384(9941):438-454.

10. Baqui AH, El-Arifeen S, Darmstadt GL, Ahmed S, Williams EK, Seraji HR, et al: Effect of community-based newborn-care intervention package implemented through two service-delivery strategies in Sylhet district, Bangladesh: a cluster-randomised controlled trial. Lancet 2008, 371(9628):1936-1944.

11. Herbert HK, Lee AC, Chandran A, Rudan I, Baqui AH: Care seeking for neonatal illness in low- and middle-income countries: a systematic review. PLoS medicine 2012, 9(3):e1001183.

12. Bahl R, Martines J, Ali N, Bhan MK, Carlo W, Chan KY, et al: Research priorities to reduce global mortality from newborn infections by 2015 . Pediatr Infect Dis J 2009, 28(1 Suppl):S43-48.

13. WHO, UNICEF: Every Newborn: An action plan to end preventable newborn deaths Geneva: World Health Organisation. 2014, [cited 2014 September 2014]. Available from: http://www.who.int/maternal_child_adolescent/topics/ newborn/every-newborn-action-plan-draft.pdf.

14. Darmstadt GL, Bhutta ZA, Cousens S, Adam T, Walker N, De Bernis L: Evidence-based, cost-effective interventions: how many newborn babies can we save? Lancet 2005, 365(9463):977-988.

15. Edmond K, Zaidi A: New approaches to preventing, diagnosing, and treating neonatal sepsis. PLoS medicine 2010, 7(3):e1000213.

16. Dickson EKim, Kinney VMary, Moxon GSarah, Ashton Joanne, Zaka Nabila, Simen-Kapeu Aline, Sharma Gaurav, Kerber JKate, Daelmans Bernadette, Gülmezoglu Metin A, Mathai Matthews, Nyange Christabel, Baye Martina, Lawn EJoy: Scaling up quality care for mothers and newborns around the time of birth: an overview of methods and analyses of interventionspecific bottlenecks and solutions. BMC Pregnancy Childbirth 2015, 15(Suppl 2):S1.

17. WHO, UNICEF: Every Newborn Action Plan: Progress Report May 2015. World Health Organization; United Nations Children's Fund. 2015.

18. Singh $D$, Lample $M$, Earnest J: The involvement of men in maternal health care: cross-sectional, pilot case studies from Maligita and Kibibi, Uganda. Reprod Health 2014, 11:68.

19. Plantin L, Olukoya A, Pernilla N: Positive health outcomes of fathers' involvement in pregnancy and childbirth paternal support: a scope study literature review. Fathering A Journal of Theory Research and Practice about Men as Fathers 2011, 9(1):87-102.

20. Gogia S, Ramji S, Gupta P, Gera T, Shah D, Mathew JL, et al: Community based newborn care: a systematic review and metaanalysis of evidence: UNICEF-PHFI series on newborn and child health, India. Indian Pediatr 2011, 48(7):537-546.

21. Bhandari N, Mazumder S, Taneja S, Sommerfelt H, Strand TA, Group IES: Effect of implementation of Integrated Management of Neonatal and Childhood IIIness (IMNCI) programme on neonatal and infant mortality: cluster randomised controlled trial. BMJ 2012, 344:e1634.

22. Healy CM, Baker CJ: Maternal immunization. Pediatr Infect Dis J 2007, 26(10):945-948.

23. Dawson P, Pradhan $Y$, Houston R, Karki S, Poudel D, Hodgins S: From research to national expansion: 20 years' experience of communitybased management of childhood pneumonia in Nepal. Bull World Health Organ 2008, 86(5):339-343.

24. Enweronu-Laryea Christabel, Dickson EKim, Moxon GSarah, SimenKapeu Aline, Nyange Christabel, Niermeyer Susan, Bégin France, Sobel LHoward, Lee CCAnne, von Xylander Ritter Severin, Lawn EJoy: Basic newborn care and neonatal resuscitation: a multi-country analysis of health system bottlenecks and potential solutions. BMC Pregnancy Childbirth 2015, 15(Suppl 2):S4.

25. Sharma Gaurav, Mathai Matthews, Dickson Eva Kim, Weeks Andrew, Hofmeyr Justus G, Lavender Tina, Day Tina Louise, Mathews Elizabeth Jiji, Fawcus Sue, Kapeu Simen Aline, de Bernis Luc: Quality care during labour and birth: a multi-country analysis of health system bottlenecks and potential solutions. BMC Pregnancy Childbirth 2015, 15(Suppl 2):S2.

26. Zaidi AK, Ganatra HA, Syed S, Cousens S, Lee AC, Black R, et al: Effect of case management on neonatal mortality due to sepsis and pneumonia. BMC Public Health 2011, 11(Suppl 3):S13. 
27. UNICEF: Management of sick children by community health workers: Intervention models and programme examples. United Nation's Children's Fund and World Health Organization; 2006.

28. Waiswa P, Kallander K, Peterson S, Tomson G, Pariyo GW: Using the three delays model to understand why newborn babies die in eastern Uganda. Trop Med Int Health 2010, 15(8):964-972.

29. Olaniran N, Offiong S, Ottong J, Asuquo E, Duke F: Mobilizing the community to utilize obstetric services, Cross River State, Nigeria. International Journal of Gynecology and Obstetrics 1997, 59(Suppl 2):S181-S189.

30. Maiga Z, Traore NF, El Abassi A: La réforme du secteur santé au Mali (1989-1996). Studies in Health Services Organisation \& Policy 12 ITGPress, Antwerpen; 1999.

31. Knippenberg R, Lawn JE, Darmstadt GL, Begkoyian G, Fogstad H, Walelign N, Paul VK: Systematic scaling up of neonatal care in countries. Lancet 2005, 365(9464):1087-1098.

32. Lawn JE, Kerber K, Enweronu-Laryea C, Cousens S: 3.6 million neonatal deaths-what is progressing and what is not? Semin Perinatol 2010, 34(6):371-386.

33. Moxon GSarah, Lawn EJoy, Dickson EKim, Simen-Kapeu Aline, Gupta Gagan, Deorari Ashok, Singhal Nalini, New Karen, Kenner Carole, Bhutani Vinod, Kumar Rakesh, Molyneux Elizabeth, Blencowe Hannah: Inpatient care of small and sick newborns: a multi-country analysis of health system bottlenecks and potential solutions. BMC Pregnancy Childbirth 2015, 15(Suppl 2):S7.

34. Haines A, Sanders D, Lehmann U, Rowe AK, Lawn JE, Jan S, et al: Achieving child survival goals: potential contribution of community health workers. Lancet 2007, 369(9579):2121-2131.

35. Khanal S, Sharma J, Gc VS, Dawson P, Houston R, Khadka N, Yengden B: Community health workers can identify and manage possible infections in neonates and young infants: MINI-a model from Nepal. J Health Popul Nutr 2011, 29(3):255-264.

36. de Sousa A, Tiedje KE, Recht J, Bjelic I, Hamer DH: Community case management of childhood illnesses: policy and implementation in Countdown to 2015 countries. Bull World Health Organ 2012, 90(3):183-190.

37. Mohan P, Kishore B, Singh S, Bahl R, Puri A, Kumar R: Assessment of implementation of integrated management of neonatal and childhood illness in India. J Health Popul Nutr 2011, 29(6):629-638.

38. WHO: Integrated management of childhood illness: Chart Booklet. Geneva: World Health Organization; 2014.

39. Mittal K, Gupta V, Khanna P, Kaushik JS, Sharma A: Evaluation of Integrated Management of Neonatal and Childhood Illness (IMNCI) algorithm for diagnosis and referral in under-five children. Indian J Pediatr 2014, 81(8):797-799

40. Stoll BJ, Bhan MK: New research on community management of severe neonatal infections: an overview. Pediatr Infect Dis J 2013, 32(Suppl 1): S1-2.

41. Afnan-Holmes $H$, Magoma M, John T, Levira F, Msemo G, Armstrong CE, et al: Tanzania's Countdown to 2015: analysis of two decades of progress and gaps for reproductive, maternal, newborn and child health, to inform post-2015 priorities. Lancet Global Health 2015, 3(7): e396-e409.

42. Irimu GW, Greene A, Gathara D, Kihara H, Maina C, Mbori-Ngacha D, et al: Explaining the uptake of paediatric guidelines in a Kenyan tertiary hospital-mixed methods research. BMC Health Serv Res 2014, 14:119.

43. Jacob ST, Lim M, Banura P, Bhagwanjee S, Bion J, Cheng AC, et al: Integrating sepsis management recommendations into clinical care guidelines for district hospitals in resource-limited settings: the necessity to augment new guidelines with future research. BMC medicine 2013, 11:107.

44. Baelani I, Jochberger S, Laimer T, Rex C, Baker T, Wilson IH, et al: Identifying resource needs for sepsis care and guideline implementation in the Democratic Republic of the Congo: a cluster survey of 66 hospitals in four eastern provinces. Middle East J Anaesthesiol 2012, 21(4):559-575.

45. Rasanathan K, Muniz M, Bakshi S, Kumar M, Solano A, Kariuki W, et al: Community case management of childhood illness in sub-Saharan Africa - findings from a cross-sectional survey on policy and implementation. Journal of global health 2014, 4(2):020401.

46. Musiime GM, Seale AC, Moxon SG, Lawn JE: Risk of gentamicin toxicity in neonates treated for possible severe bacterial infection in low and middle income countries (IN PRESS). 2015.
47. Moxon GSarah, Ruysen Harriet, Kerber JKate, Amouzou Agbessi, Fournier Suzanne, Grove John, Moran CAllisyn, Vaz MELara, Blencowe Hannah, Conroy Niall, Gülmezoglu Metin A, Vogel PJoshua, Rawlins Barbara, Sayed Rubayet, Hill Kathleen, Vivio Donna, Qazi Shamim, Sitrin Deborah, Seale CAnna, Wall Steve, Jacobs Troy, Ruiz Peláez Gabriel Juan, Guenther Tanya, Coffey SPatricia, Dawson Penny, Marchant Tanya, Waiswa Peter, Deorari Ashok, Enweronu-Laryea Christabel, Arifeen El Shams, Lee CCAnne, Mathai Matthews, Lawn EJoy: Count every newborn; a measurement improvement roadmap for coverage data. BMC Pregnancy Childbirth 2015, 15(S2):S8.

48. Kissoon N, Burns J: Who should get pediatric intensive care when not all can? A call for international guidelines on allocation of pediatric intensive care resources*. Pediatr Crit Care Med 2014, 15(1):82-83.

49. Braun R, Catalani C, Wimbush J, Israelski D: Community health workers and mobile technology: a systematic review of the literature. PloS one 2013, 8(6):e65772.

50. Hazel E, Requejo J, David J, Bryce J: Measuring coverage in MNCH: evaluation of community-based treatment of childhood illnesses through household surveys. PLoS medicine 2013, 10(5):e1001384.

51. Bhutta ZA, Zaidi AK, Thaver D, Humayun Q, Ali S, Darmstadt GL: Management of newborn infections in primary care settings: a review of the evidence and implications for policy? Pediatr Infect Dis J 2009, 28(1 Suppl):S22-30.

52. Kerber JKate, Mathai Matthews, Lewis Gwyneth, Flenady Vicki, HM Erwich Jaap Jan, Segun Tunde, Aliganyira Patrick, Abdelmegeid Ali, Allanson Emma, Roos Nathalie, Rhoda Natasha, Lawn EJoy, Pattinson Robert: Counting every stillbirth and neonatal death to improve quality of care for every pregnant woman and her baby. BMC Pregnancy Childbirth 2015, 15(S2):S9.

53. Campbell H, El Arifeen S, Hazir T, O'Kelly J, Bryce J, Rudan I, Qazi SA: Measuring coverage in $\mathrm{MNCH}$ : challenges in monitoring the proportion of young children with pneumonia who receive antibiotic treatment. PLoS medicine 2013, 10(5):e1001421.

54. WHO: Pocket book of hospital care for children: Guidelines of the management of common childhood illnesses. Geneva: World Health Organization; 2013.

55. Zaidi AK, Baqui AH, Qazi SA, Bahl R, Saha S, Ayede Al, et al: Scientific rationale for study design of community-based simplified antibiotic therapy trials in newborns and young infants with clinically diagnosed severe infections or fast breathing in South Asia and sub-Saharan Africa. Pediatr Infect Dis J 2013, 32(9 Suppl 1):S7-11.

56. Esamai F, Tshefu AK, Ayede Al, Adejuyigbe EA, Wammanda RD, Baqui AH, et al: Ongoing trials of simplified antibiotic regimens for the treatment of serious infections in young infants in South Asia and sub-Saharan Africa: implications for policy. Pediatr Infect Dis J 2013, 32(9 Suppl 1): S46-49.

doi:10.1186/1471-2393-15-S2-S6

Cite this article as: Simen-Kapeu et al:: Treatment of neonatal infections: a multi-country analysis of health system bottlenecks and potential solutions. BMC Pregnancy and Childbirth 2015 15(Suppl 2):S6.

\section{Submit your next manuscript to BioMed Central and take full advantage of:}

- Convenient online submission

- Thorough peer review

- No space constraints or color figure charges

- Immediate publication on acceptance

- Inclusion in PubMed, CAS, Scopus and Google Scholar

- Research which is freely available for redistribution 